\title{
Use of Steroid Profiling by UPLC-MS/MS as a Second Tier Test in Newborn Screening for Congenital Adrenal Hyperplasia: The Utah Experience
}

\author{
ELISABETH SCHWARZ, AIPING LIU, HARPER RANDALL, CHRISTA HASLIP, FAY KEUNE, MARY MURRAY, \\ NICOLA LONGO, AND MARZIA PASQUALI
}

ARUP Institute for Clinical and Experimental Pathology [E.S., A.L., N.L., M.P.], ARUP Laboratories, Salt Lake City, Utah 84108; ARUP Laboratories Inc. [C.H., N.L., M.P.], Salt Lake City, Utah 84108; Departments of Pediatrics [M.M., N.L.], and Pathology [N.L., M.P.], University of Utah, Salt Lake City, Utah 84132; Newborn Screening Follow-up Program [H.R., F.K.], Utah Department of Health, Salt Lake City, Utah 84114

\begin{abstract}
Newborn screening allows the diagnosis of congenital adrenal hyperplasia $(\mathrm{CAH})$ before symptoms appear, preventing the severe and potentially life-threatening crisis associated with this disease in infancy. Traditional screening by enzyme immunoassay results in a large number of false positives. To reduce the number of unnecessary tests, anxiety to families and physicians, and the burden to the newborn screening follow-up program, we implemented a second-tier test for CAH using steroid profiling by an ultraperformance liquid chromatography-tandem mass spectrometry. We measured three steroids: 17-hydroxyprogesterone, androstenedione, and cortisol and correlated them with the age of infant at the time of sample collection and birth weight. Both age at collection and birth weight affected the levels of adrenal steroids, but the use of appropriate cut offs and analyte ratios allowed the identification of infants with CAH. This approach was effective in identifying infants with $\mathrm{CAH}$, with both salt-wasting and simple virilizing forms, while reducing the false-positive rate from 2.6 to $0.09 \%$. (Pediatr Res 66: 230-235, 2009)
\end{abstract}

$\mathrm{C}$ ongenital adrenal hyperplasia (CAH) is a group of autosomal recessive disorders caused by defects in adrenal steroid biosynthesis. The most common form, accounting for $90 \%$ of CAH cases, is caused by alterations in the CYP 21 gene, resulting in absent or decreased activity of 21hydroxylase (1), the enzyme that converts 17-hydroxyprogesterone (17-OHP) to 11-deoxycortisol and progesterone to deoxycorticosterone. Impaired activity of this enzyme results in increased 17-OHP, defective synthesis of cortisol and mineralcorticoids, increased synthesis of androstenedione, and decreased central feedback (increased production of adrenocorticotropic hormone) resulting in adrenal hyperplasia, virilization, and salt-wasting crisis, which can be lethal (2).

All states in the United States currently screen newborns for $\mathrm{CAH}$; most measure 17-OHP in blood spots using commercial enzyme immunoassay (EIA) kits (3-5). This methodology, however, causes a great number of false-positive results due to

Received February 9, 2009; accepted April 1, 2009.

Correspondence: Elisabeth Schwarz, M.S., ARUP Institute for Clinical and Experimental Pathology, 500 Chipeta Way, Salt Lake City, UT 84108; e-mail: schwarl@ aruplab.com

Supported by ARUP Institute for Clinical and Experimental Pathology, ARUP Laboratories, Salt Lake City, Utah. the lack of antibody specificity and high cross-reactivity with other endogenous compounds $(6,7)$. In addition, increased serum concentrations of 17-OHP are associated with low birth weight and illness, causing an even higher incidence of falsepositives in the premature and sick infant population. Adjusting the cut off of 17-OHP for gestational age and birth weight improves the specificity of the test $(8,9)$. Despite this reduction in the number of false-positive results, particularly among the low birth weight infants, CAH screening still has the lowest predictive value among newborn screening tests when measurement of 17-OHP concentration alone is used (10-12).

As an alternative to immunoassay, gas chromatographymass spectrometry and liquid chromatography-tandem mass spectrometry (LC-MS/MS) can detect individual steroids and, therefore, alleviate the issues of cross reactivity and specificity, but these methods require derivatization of samples, and they are more time consuming (13-20). Second-tier tests (i.e. tests performed on the same specimen used for a primary screen) using steroid profiling by LC-MS/MS can significantly increase the specificity and sensitivity of $\mathrm{CAH}$ newborn screening (21-24). With this approach, the concentration of 17-OHP is measured by LC-MS/MS, and, after extraction with organic solvents, it is compared with the concentrations of other steroids in the affected pathways to further reduce the number of false-positive screens (21-24). Patients with CAH have elevated 17-OHP and androstenedione, with a relatively low cortisol, resulting in a markedly increased ratio of (17-OHP + androstenedione)/cortisol. The use of this ratio helps eliminate most of the infants with elevated 17-OHP because of stress, illness, or prematurity (21-24).

Additional steroids, such as 11-deoxycortisol and 21deoxycortisol, can be monitored using LC-MS/MS to detect the additional $5 \%$ of patients with CAH due to deficiency of 11-hydroxylase, which converts 11-deoxycortisol to cortisol and deoxycorticosterone to corticosterone $(23,24)$. Additional

Abbreviations: 17-OHP, 17-hydroxyprogesterone; CAH, congenital adrenal hyperplasia; EIA, enzyme immunoassay; LC-MS/MS, liquid chromatography-tandem mass spectrometry; UPLC, ultra performance liquid chromatography 
ratios using these steroids have been shown to be helpful in identifying these infants $(23,24)$.

In this study, we simplify the extraction and optimize the quantitation of 17-OHP, androstenedione, and cortisol to improve an existing method $(21,22)$. The ratio between the steroids that accumulate in CAH (17-OHP and androstenedione) and cortisol was calculated using concentrations of analytes rather than peak areas, which greatly improves specificity. The availability of true concentrations (rather than peak areas) of these steroids enabled us to determine their changes with age and birth weight in infants that required second-tier testing. A major improvement of our method was the use of an ultra performance LC-MS/MS (UPLC-MS/MS) system. The use of UPLC increased resolution, sensitivity, and speed of analysis, resulting in complete separation of 17-OHP, androstenedione, and cortisol in less than $3 \mathrm{~min}$, a significant step that would allow the use of this technique as the primary screen for CAH.

\section{METHOD}

This protocol was reviewed by the University of Utah and the Utah Department of Health Investigational Review Boards and classified as exempt. No informed consent was required from the participants. All blood spots of infants born in Utah are tested for CAH using an EIA (Neo-Genesis Accuwell, Clackamas, OR) method as a primary screen that measures the concentration of 17-OHP. Blood spots with elevated 17-OHP by this primary screen are submitted for steroid profiling by UPLC-MS/MS. We have evaluated the results obtained in 13 mo of screening using this method.

Samples. All samples used in this study came from the Utah Newborn Screening Program and was collected in the first week of life. Infants were divided in three groups based on birth weight: group 1, less than $1500 \mathrm{~g}$; group 2, between $1500 \mathrm{~g}$ and $2500 \mathrm{~g}$; group 3, greater than $2500 \mathrm{~g}$. Blood spots obtained from the Centers for Disease Control and Prevention were used as quality controls for the validation of the method.

Sample analysis. Calibrators of the three steroids were prepared in whole blood at different concentrations and spotted on filter paper. Approximately 4.8-mm (3/16") punches from blood spots of calibrators, controls, and samples were extracted with $200 \mu \mathrm{L}$ extraction solution (80:20 acetonitrile:water), containing deuterated internal standards for each analyte in a flat bottom 96-well plate. The plate was covered and agitated vigorously for $30 \mathrm{~min}$ in a microplate shaker, then centrifuged for $10 \mathrm{~min}$ at $1500 \times \mathrm{g}$. The extract was then transferred to a 1-mL V-bottom 96-well plate (Waters, Chicago, IL) and dried under gentle nitrogen flow using a SPE-Dry 96 Nitrogen evaporator (upper manifold at $50^{\circ} \mathrm{C}$ and lower manifold at $70^{\circ} \mathrm{C}$ ). The dry residue was reconstituted with $50 \mu \mathrm{L}$ of $10 \%$ acetone in water. The plate was then sealed with a clear film heat seal, agitated in a microplate shaker for $30 \mathrm{~min}$, and centrifuged at $1500 \times \mathrm{g}$ for $10 \mathrm{~min}$. Fourteen microliters of the mixture was injected in the UPLC for chromatographic separation followed by MS/MS detection. The 17-OHP, $\mathrm{d}_{8}-17-\mathrm{OHP}$, androstenedione, $\mathrm{d}_{7}$-androstenedione, cortisol, and $\mathrm{d}_{4}$-cortisol were used as standards and internal standards, respectively, to build a calibration curve each time the assay was run.

A Waters Acquity UPLC system (Milford, MA) was used in this study for the chromatographic separation. Cortisol, androstenedione, and 17-OHP were chromatographically resolved using a reverse phase column (Acquity UPLC $\mathrm{BEH} \mathrm{C}_{18}, 1.7 \mu \mathrm{m}, 2.1 \times 50 \mathrm{~mm}$, and $0.2 \mu \mathrm{m}$ in-line precolumn filter). The LC separation was performed using a linear gradient from $60 \%$ of mobile phase A (water $+0.05 \%$ formic acid) and $40 \%$ of mobile phase B $(100 \%$ methanol) to $70 \%$ mobile phase A and $30 \%$ mobile phase B over 3 min with a flow rate of $0.6 \mathrm{~mL} / \mathrm{min}$. The column temperature was maintained at $40^{\circ} \mathrm{C}$ throughout the separation. The detection and quantitation were achieved by MS/MS using a Waters Quattro Premier XE tandem spectrometer.

The mass spectrometer was equipped with an electrospray source operating in positive ionization mode. The samples were analyzed in selective reaction monitoring mode using three different channels, the transitions monitored were cortisol (quantifier, qualifier): $363.3>121.2,363.3>97.2$; $\mathrm{d}_{4}$-cortisol (quantifier): $367.3>121.2$; androstenedione (quantifier, qualifier): $287.4>97.2,287.4>109.2 ; d_{7}$-androstenedione (quantifier): $294.3>100.1$; $17 \alpha$-OHP (quantifier, qualifier): $331.4>97.2,331.4>109.2 ; \mathrm{d}_{8}-17 \alpha$-OHP (quantifier): $339.3>100.1$. Data acquisition was performed using MassLynx 4.1 and analyzed with QuanLynx V4.0 SP4 software.
Statistical analysis. Statistical analysis of the data were performed using GraphPad Prism, version 5.01(La Jolla, CA). One-way ANOVA nonparametric analysis (Kruskal-Wallis test) was applied to determine the significance $(p<0.01)$ of the results. Linear regression analysis was performed using the same program to determine the correlation between the steroids concentration and the age or the birth weight of the infants.

\section{RESULTS}

The separation of the three steroids by UPLC was achieved within 3 min (Fig. 1). Cortisol, androstenedione, and 17-OHP were easily separated, and the use of three internal standards allowed the accurate quantitation of each analyte. The assay was linear up to $4440 \mathrm{ng} / \mathrm{mL}$ serum for all three analytes (cortisol, androstenedione, and 17-OHP), with a limit of detection of 1.7 $\mathrm{ng} / \mathrm{mL}$ serum and a limit of quantitation of $3.5 \mathrm{ng} / \mathrm{mL}$ serum. The recovery was greater than $90 \%$ for all three analytes. Within-run and between-run imprecision was less than $10 \%$.

During the 13 mo in which this method was used, 64,615 infants were screened by EIA for CAH. Approximately $1 \%$ of the infants screened weighted $<1500 \mathrm{~g}$ (group $1, n=670$ ), $6.2 \%$ weighted $1500-2500 \mathrm{~g}$ (group $2, n=4011$ ), and $92.8 \%$ weighted $>2500 \mathrm{~g}$ (group $3, n=59,934$ ). A total of $2.6 \%$ of the infants screened $(n=1709)$ had an abnormal primary screen for CAH (EIA of 17-OHP above the cut off, adjusted for birth weight) requiring second-tier test by steroid profiling using UPLC-MS/MS. In this group of infants, 146 infants (8.5\%) belonged to group 1, 610 infants $(35.7 \%)$ to group 2, and 953 infants (55.8\%) to group 3. Among the infants with abnormal primary screen, the median age at which the screening sample was collected was 2 d, with $92.6 \%$ of samples collected by $3 \mathrm{~d}$ of age. Our criteria for a positive second-tier test, requiring additional confirmatory studies and referral to the pediatric endocrinologist, was a level of 17-OHP greater than $12.5 \mathrm{ng} / \mathrm{mL}$ of serum and a concentration ratio of (androstenedione $+17-\mathrm{OHP}$ )/cortisol greater than 1.0. Of the positive infants after the second-tier test, $8.9 \%$ in group $1(n=$



Figure 1. Second-tier test by UPLC-MS/MS for CHA. Steroid profiles of normal infant $(A)$ and $\mathrm{CAH}$ infant $(B)$ were obtained with a mass spectrometer equipped with an electrospray source operating in the positive ionization mode. The samples were analyzed in the selective reaction monitoring mode using different transitions for the deuterated standards (not shown) and the natural compounds (see Methods Section). Internal standards were used for quantification, and the two panels are shown with the same scale. 
$13), 6.2 \%$ in group $2(n=38)$, and $1.4 \%$ in group $3(n=13)$ had an abnormal result and required additional confirmatory tests and referral to the pediatric endocrinologist. Of these 64, six infants were confirmed with CAH $(1: 10,769)$, five with the salt wasting and one with the simple virilizing variants (Fig. 2). Of the six cases, four were males and two were females. Both females were identified clinically by ambiguous genitalia at birth. One of the six infants had an abnormal first screen (possibly related to prematurity) but a normal level of 17-OHP $(<12.5 \mathrm{ng} / \mathrm{mL})$ with second-tier testing. However, the ratio of the concentrations of 17-OHP + androstenedione/cortisol was elevated to 6.7. This infant had received corticosteroids for management of respiratory problems before the collection of the sample. For this reason, second-tier tests with a concentration ratio greater than 4, regardless of the level of 17-OHP, were included among positive cases. This additional group increases the possibility of identifying infants who have received corticosteroids before collection of the newborn screen sample. In the 13 mo of this study, 10 infants, including the infant with $\mathrm{CAH}$, fell into this category. Even including the additional infants identified with the increased ratio, the falsepositive rate for the newborn screening was reduced from 2.64 to $0.09 \%$. To our knowledge (Utah has a single central referral center), no cases were missed by this technique.

The strategy of steroid profiling by UPLC-MS/MS after a first abnormal screen by EIA significantly reduced the falsepositive rate of newborn screening for $\mathrm{CAH}$ and, consequently, reduced the number of additional and unnecessary tests. It also reduced the anxiety to families and physicians who have to respond to the false-positive screens and signif-

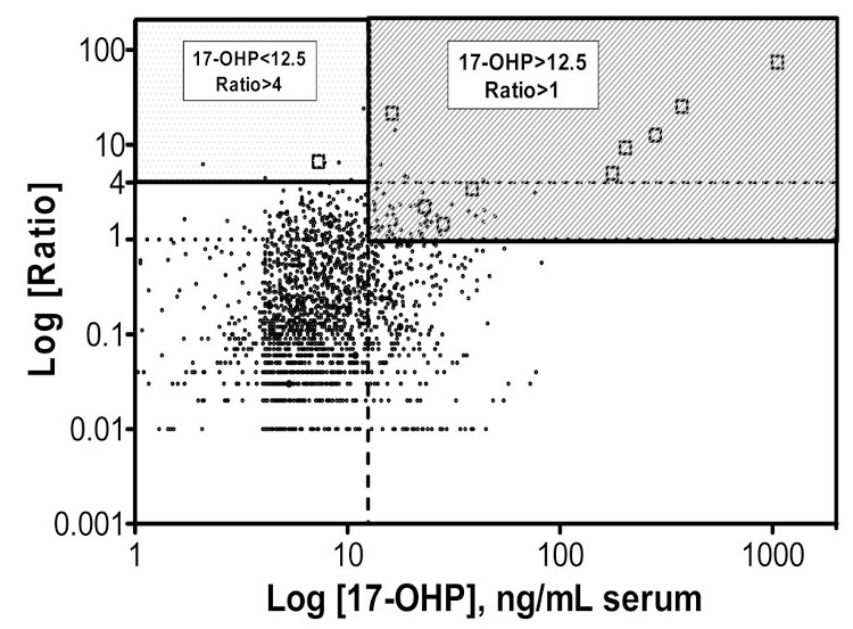

Figure 2. Second-tier testing for CHA. Samples obtained from patients with increased 17-OHP by EIA were analyzed by UPLC-MS/MS and plotted according to the log of the concentration of 17-OHP and the log of the ratio (17-OHP + androstenedione)/cortisol. The hatched area represents samples with abnormal concentration of 17-OHP ( $>12.5 \mathrm{ng} / \mathrm{mL}$ serum $)$ and abnormal ratio (17-OHP + androstenedione)/cortisol $>1$, requiring additional tests and referral to pediatric endocrinology. The dotted area represents samples with normal concentration of $17-\mathrm{OHP}$ but ratio $>4$. Follow-up of these samples depended on whether corticosteroids were administered to the infant before sample collection. Open squares $(\square)=$ infants with $\mathrm{CAH}$ (included in the graph are values from infants identified during the 13 mo of this study and beyond); $\operatorname{dots}(\mathbf{0})=$ unaffected infants. icantly reduced the burden to the newborn screening follow-up program responding to an abnormal screen.

The 17-OHP levels, measured by EIA, decrease with increasing birth weight and increasing age at collection (11). We evaluated the concentrations of 17-OHP, androstenedione, and cortisol in infants without $\mathrm{CAH}$ in our population as a function of birth weight and age at the time of collection. Androstenedione did not change significantly with birth weight (data not shown). By contrast, there were significant changes of both 17-OHP and cortisol with increasing birth weight (Fig. $3)$. When infants were divided into the three groups based on birth weight, the decline in cortisol levels occurred in infants weighing $<1500 \mathrm{~g}$, whereas the levels stabilized (1500-2500 g) or slightly increased in infants weighing $>2500 \mathrm{~g}$ (Fig. 3, middle panels). For 17-OHP, a significant decline occurred in infants weighing $<2500 \mathrm{~g}$, whereas the levels stabilized in infants weighing $>2500 \mathrm{~g}$ (Fig. 3, upper panels).

There was no significant correlation between androstenedione or 17-OHP and infant age at collection (data not shown). By contrast, cortisol significantly declined with increasing infant age (Fig. 3, lower panels). When the three groups of infants were analyzed, a significant negative correlation was observed in groups 2 (birth weight $1500-2500 \mathrm{~g}$ ) and 3 (birth weight $>2500 \mathrm{~g}$ ), but not in group 1 (birth weight $<1500 \mathrm{~g}$ ).

The ratio 17-OHP/cortisol can identify patients with CAH. It has been applied mainly to studies done in plasma; very few data are available on the use of this ratio in newborns' blood spots (23). In our population, there was a significant $(p<$ 0.05 ) correlation between the ratio of $17-\mathrm{OHP} /$ cortisol and both infant age at sample collection (increase with age) and birth weight (decrease with increasing birth weight), making this ratio less useful as a discriminant (Fig. 4). By contrast, the ratio of (17-OHP + androstenedione)/cortisol did not change significantly with either age at collection or birth weight (Fig. 4). For completeness, we also evaluated the ratio of androstenedione/cortisol. Although this ratio did not change significantly with either age at collection or birth weight (Fig. 4), the level of androstenedione varied widely, often falling close to the limit of quantitation, whereas cortisol was often, especially in the smallest infants, very high, resulting in an extremely low value of the ratio.

The average concentration of androstenedione among the three birth weight groups was not significantly different, whereas the concentration was significantly increased in infants with CAH compared with controls (Fig. 5, $p<0.01$ ) in all groups (Fig. 5A). The mean and median concentrations of 17-OHP decreased with increasing birth weight and were significantly (ANOVA, $p<0.01$ ) higher in CAH infants than in unaffected infants, independent from birth weight (Fig. $5 B$ ). The cortisol concentration did not change significantly with birth weight but was significantly lower in infants with $\mathrm{CAH}$ than in unaffected infants (Fig. 5C) in all groups.

Both the 17-OHP/cortisol and the (17-OHP + androstenedione)/cortisol ratio were significantly higher in infants with CAH compared with unaffected infants of any birth weight (Fig. 5D and E). In addition, the androstenedione/ cortisol ratio was significantly higher in infants with $\mathrm{CAH}$ than in unaffected infants (Fig. $5 F$ ). 

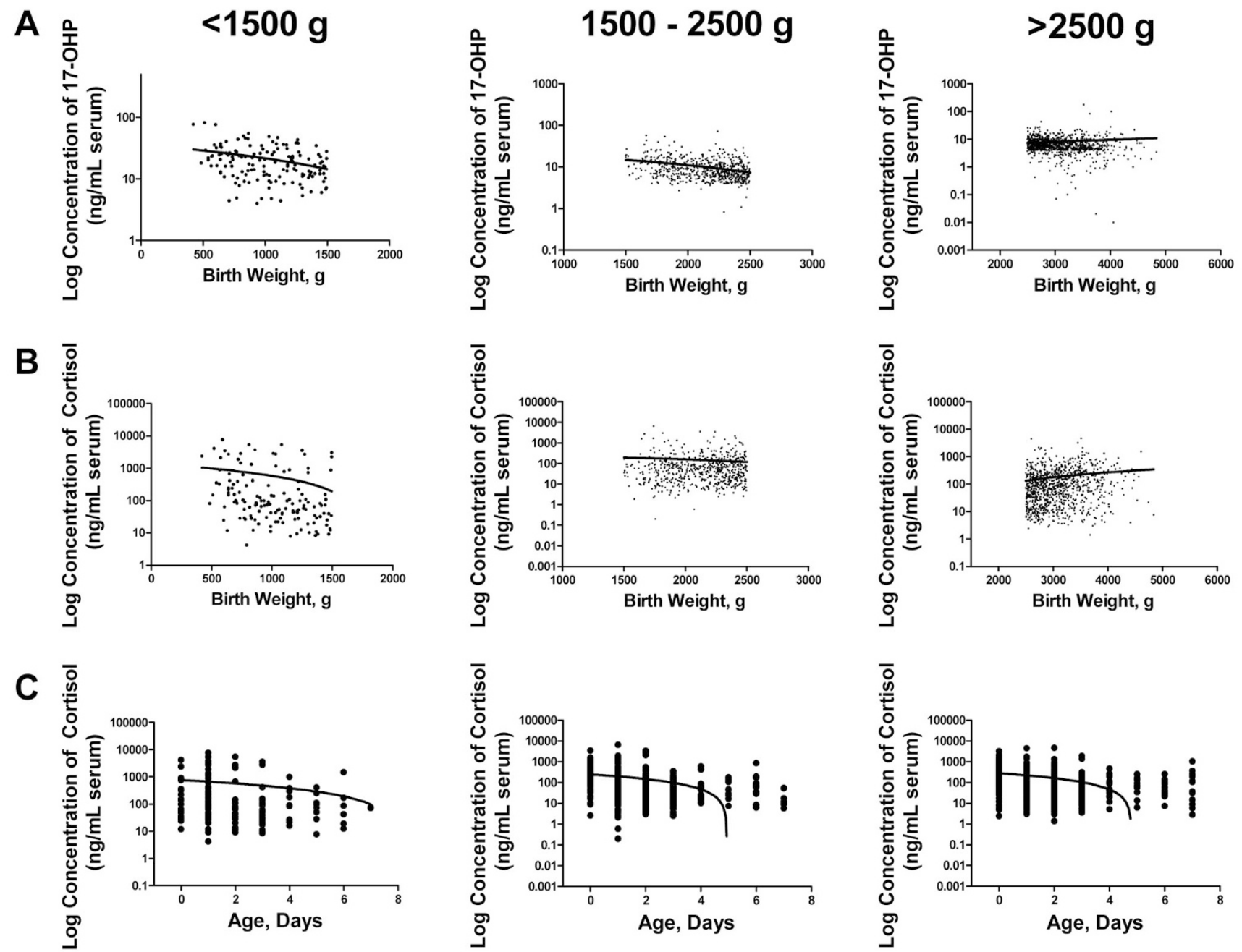

Figure 3. Correlation between the concentrations of $(A)$ 17-OHP, $(B)$ cortisol and birth weight in unaffected infants within the three groups of birth weight: $<1500 \mathrm{~g}(p<0.001$ for 17-OHP, $p=0.023$ for cortisol); $1500-2500 \mathrm{~g}(p<0.001$ for 17-OHP, $p=0.235$ for cortisol); $>2500 \mathrm{~g}(p=0.537$ for $17-\mathrm{OHP}, p<$ 0.001 for cortisol). $C$, Correlation between the concentration of cortisol and age at collection of sample in unaffected infants within the three groups of birth weight: $<1500 \mathrm{~g}(p=0.104) ; 1500-2500 \mathrm{~g}(p<0.0001) ;>2500 \mathrm{~g}(p<0.0001)$.
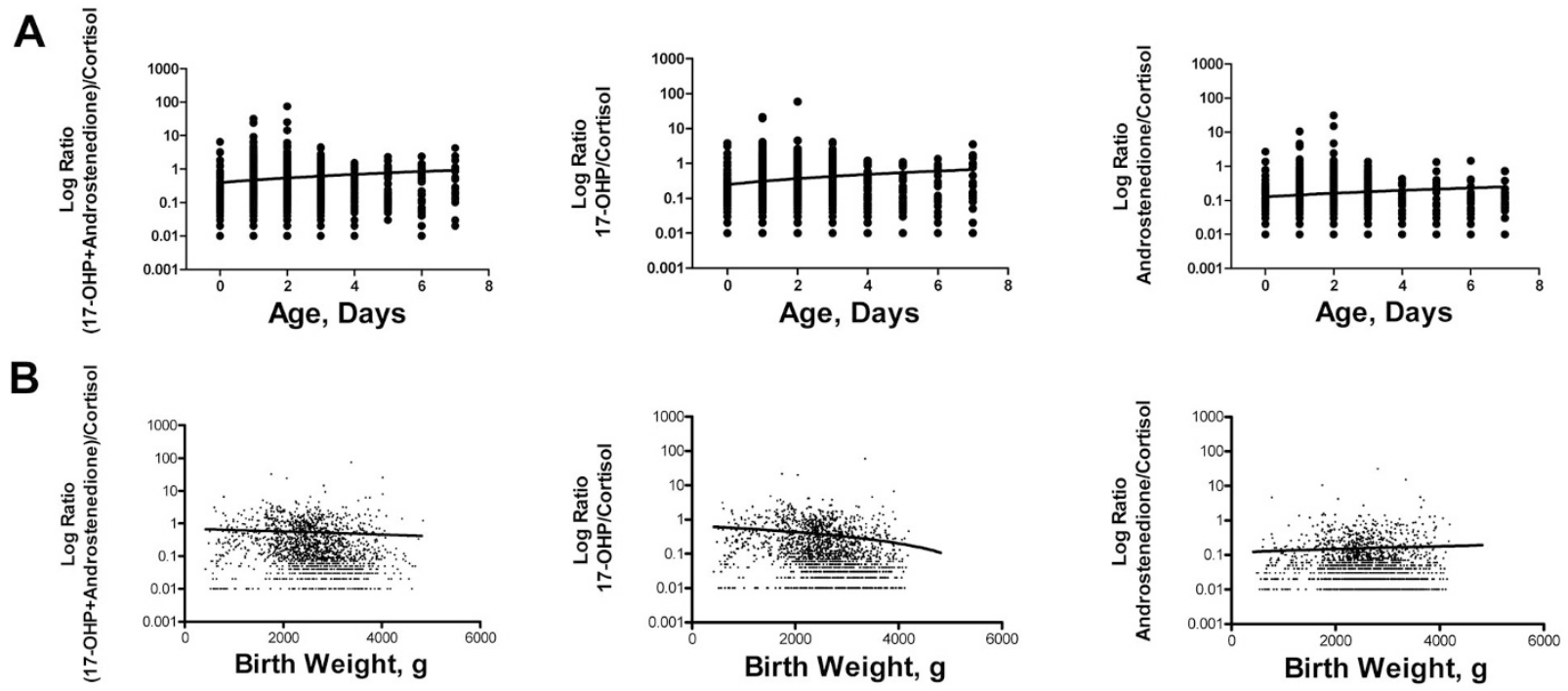

Figure 4. Correlation between $(A)$ age of collection and the ratios of (17-OHP + androstenedione $) /$ cortisol $(p=0.058)$; 17-OHP/cortisol $(p=0.034)$; androstenedione/cortisol $(p=0.254)$ and $(B)$ birth weight and the ratios (17-OHP + androstenedione $) /$ cortisol $(p=0.412)$; 17-OHP/cortisol $(p=0.033)$; androstenedione/cortisol $(p=0.589)$ in all unaffected infants. 

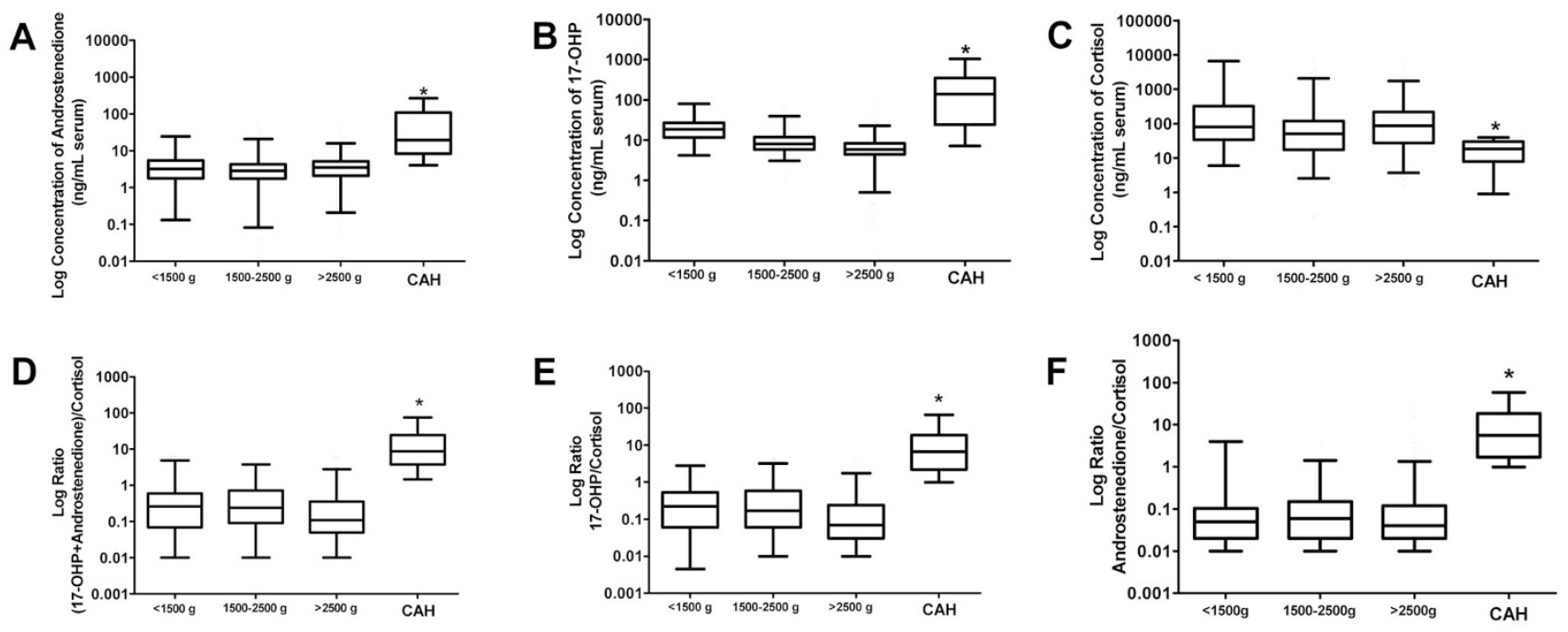

Figure 5. Concentrations, in logarithmic scale, of androstenedione (A), 17-OHP $(B)$, cortisol $(C)$, and ratios of (17-OHP + androstenedione)/cortisol $(D)$, 17-OHP/cortisol $(E)$, androstenedione/cortisol $(F)$ in unaffected infants (divided in groups according to their birth weight) and infants with CAH. *significant $(p<$ 0.05) difference between infants with $\mathrm{CAH}$ and unaffected infants.

\section{DISCUSSION}

Neonatal screening can identify infants at risk for CAH but results in a large number of false positives when only 17-OHP (measured with EIA methods) is used as marker. Correction for gestational age and birth weight reduces the number of false positives $(10,11)$, but still a large number of samples have an elevated concentration of 17-OHP, resulting in intense follow-up activities to confirm the diagnosis. The use of LC-MS/MS for steroid profiling as a second-tier test improves the specificity of the neonatal screening for CAH (21-24). In this study, we further improve the specificity of steroids profiling using UPLC. This technology improved the separation and reduced the time of analysis (Fig. 1). In addition, we used analyte concentrations (rather than peak areas) of analytes in the calculation of the ratio of (17-OHP + androstenedione)/cortisol. This was possible by incorporating internal standards for each steroid measured and resulted in better reproducibility and consistency of ratios. Using this approach, the positive predictive value of $\mathrm{CAH}$ screening improved significantly from $0.4 \%$ with EIA to $9.4 \%$ with second-tier test by UPLC-MS/MS. This represents an improvement even when compared with the published positive predictive value of $4.7 \%$ of the original method (22).

In our population, the highest percentage of abnormal, first screening results for CAH (146 of 670 or $21.8 \%$ ) was in the group of infants with the lowest birth weight $(<1500 \mathrm{~g})$ followed by those with intermediate birth weight (1500-2500 g, 610 of 4011 or $15.2 \%$ ) and those with the highest weight (>2500 g, 953 of 59,934 or $1.6 \%$ ). This persisted even after second-tier testing, with 13 of 670 infants $(1.9 \%)$ with the lowest birth weight $(<1500 \mathrm{~g})$ remaining abnormal compared with 38 of $4011(0.95 \%)$ for the group with the intermediate weight $(1500-2500 \mathrm{~g})$, and 13 of $59,934(0.02 \%)$ for the group weighting $>2500 \mathrm{~g}$. This is not surprising, considering that smaller infants are most likely to have immature adrenal function and to be ill or stressed, conditions that will increase the level of 17-OHP. This was supported by our measurement of 17-OHP and the observed decline with an increased in birth weight (Fig. 3). In all cases, infants without $\mathrm{CAH}$ were well separated from infants with $\mathrm{CAH}$ when the ratio of (17-OHP+ androstenedione)/cortisol was used to discriminate (Figs. 2 and 5). The relatively few infants with a persistent elevated ratio probably have delayed expression of enzymes, such as 11-hydroxylase, involved in steroid synthesis. The evaluation of different ratios has confirmed that the (17-OHP + androstenedione)/cortisol ratio is the best discriminant for CAH (22). If additional steroids are measured as part of the screening, such as 11- and 21- deoxycortisol, other ratios could be considered $(23,24)$.

The major confounding factor in our experience is the administration of steroids before sample collection. One infant with $\mathrm{CAH}$, who received corticosteroids before the collection of the newborn screen sample, had a normal level of 17-OHP (7.3 ng/mL serum) but a markedly elevated ratio of (17-OHP + androstenedione)/cortisol (6.7). This might be explained with response to corticosteroids and timing of sample collection. Except for this infant, all confirmed CAH cases were full-term ( $>2500 \mathrm{~g}$ birth weight) and not sick at the time of sample collection. Their 17-OHP concentration and steroid concentration ratio were in the highest percentile of their birth weight group. To possibly identify potential missed cases of CAH or milder variants of $\mathrm{CAH}$, we are following up all infants with a (17-OHP + androstenedione)/cortisol ratio greater than 4 to see if they received corticosteroids before collection of the sample. However, other causes of false-negative results might not have been identified in this study, for example, infants of mothers who received corticosteroids close to the time of delivery. Primary care physicians should be aware of this and should evaluate a child for $\mathrm{CAH}$ despite a normal screen result in such cases.

There was a wide range of 17-OHP concentration in infants with $\mathrm{CAH}$, with the minimum value of $7.3 \mathrm{ng} / \mathrm{mL}$ serum and 
a maximum value of $1054 \mathrm{ng} / \mathrm{mL}$ serum. The highest values were associated with salt-wasting forms of $\mathrm{CAH}$. Among the unaffected infants, the range of concentration of 17-OHP was equally wide, with the highest values in the infants with the lowest birth weight as previously observed (Figs. 3 and 5). For cortisol, the decline in concentration was significant only in infants weighting $<1500 \mathrm{~g}$, although the average cortisol concentration was higher in smaller infants (Fig. 5). This suggests that smaller infants remain significantly stressed and continue to produce more cortisol at least up to $7 \mathrm{~d}$ of age. By contrast, cortisol production declines in older infants as they recover from the stress of birth.

It was interesting that $93 \%$ of infants requiring additional testing (with an abnormal second-tier test result) were admitted to neonatal intensive care units because of prematurity or illness. This fact can also explain the positive correlation between cortisol and birth weight in group 3 (>2500 g, Fig. 3). The majority of these infants were admitted to neonatal intensive care units because of illness. Therefore, this group represents a population of stressed infants, explaining the higher cortisol.

Only the concentration of cortisol changed significantly with the time at which the sample was collected (Fig. 3), whereas no significant correlation was observed with17-OHP or androstenedione (Fig. 3). Despite changes with birth weight and time of collection, the different ratios among steroids remained relatively constant (Fig. 4), with the (17-OHP + androstenedione)/cortisol ratio providing the best discriminant in infants with CAH (Fig. 5).

In summary, our data show that the highest rate of false positive is observed in the lowest birth weight and sick infants. The use of second-tier testing, although not completely eliminating false-positive results, greatly reduces the number of false-positive screens and the number of additional tests to prove or disprove the diagnosis.

Acknowledgments. We thank Jan Kilpack, Karen Roylance, and Norman Brown from Utah Department of Health; Sam Parker and David Davis from ARUP Institute for Clinical and Experimental Pathology; and Jennifer Blackley, Keerti Rathi, and Leah Richardson from ARUP Newborn Screening Laboratories for their assistance.

\section{REFERENCES}

1. Speiser PW, White PC 2003 Congenital adrenal hyperplasia. N Engl J Med 349:776-788

2. Honour JW, Torresani T 2001 Evaluation of neonatal screening for congenital adrenal hyperplasia. Horm Res 55:206-211
3. Therrell BL Jr, Berenbaum SA, Manter-Kapanke V, Simmank J, Korman K, Prentice L, Gonzalez J, Gunn S 1998 Results of screening 1.9 million Texas newborns for 21-hydroxylase-deficient congenital adrenal hyperplasia. Pediatrics 101:583-590

4. Pang SY, Wallace MA, Hofman L, Thuline HC, Dorche C, Lyon IC, Dobbins RH, Kling S, Fujieda K, Suwa S 1988 Worldwide experience in newborn screening for classical congenital adrenal hyperplasia due to 21-hydroxylase deficiency. Pediatrics 81:866-874

5. Brosnan PG, Brosnan CA, Kemp SF, Domek DB, Jelley DH, Blackett PR, Riley WJ 1999 Effect of newborn screening for congenital adrenal hyperplasia. Arch Pediatr Adolesc Med 153:1272-1278

6. Makela SK, Ellis G 1988 Nonspecificity of a direct 17 alpha-hydroxyprogesterone radioimmunoassay kit when used with samples from neonates. Clin Chem 34:20702075

7. al Saedi S, Dean H, Dent W, Stockl E, Cronin C 1996 Screening for congenital adrenal hyperplasia: the Delfia Screening Test overestimates serum 17hydroxyprogesterone in preterm infants. Pediatrics 97:100-102

8. Huysman MW, Hokken-Koelega AC, De Ridder MA, Sauer PJ 2000 Adrenal function in sick very preterm infants. Pediatr Res 48:629-633

9. al Saedi S, Dean H, Dent W, Cronin C 1995 Reference ranges for serum cortisol and 17-hydroxyprogesterone levels in preterm infants. J Pediatr 126:985-987

10. Allen DB, Hoffman GL, Fitzpatrick P, Laessig R, Maby S, Slyper A 1997 Improved precision of newborn screening for congenital adrenal hyperplasia using weightadjusted criteria for 17-hydroxyprogesterone levels. J Pediatr 130:128-133

11. Olgemoller B, Roscher AA, Liebl B, Fingerhut R 2003 Screening for congenital adrenal hyperplasia: adjustment of 17-hydroxyprogesterone cut-off values to both age and birth weight markedly improves the predictive value. J Clin Endocrinol Metab 88:5790-5794

12. Watterberg KL, Gerdes JS, Cook KL 2001 Impaired glucocorticoid synthesis in premature infants developing chronic lung disease. Pediatr Res 50:190-195

13. Wei JQ, Wei JL, Lucarelli C, Zhou XT, Wang DQ, Dai WJ, Li S, Li SM, Liu RT 1992 Serum steroid hormonal profiles by reversed-phase liquid chromatography in patients with 17-hydroxylase deficiency and in an affected family. Clin Chem 38:76-82

14. Etter ML, Eichhorst J, Lehotay DC 2006 Clinical determination of 17hydroxyprogesterone in serum by LC-MS/MS: comparison to Coat-A-Count RIA method. J Chromatogr B Analyt Technol Biomed Life Sci 840:69-74

15. Lai CC, Tsai CH, Tsai FJ, Wu JY, Lin WD, Lee CC 2002 Monitoring of congenital adrenal hyperplasia by microbore HPLC-electrospray ionization tandem mass spectrometry of dried blood spots. Clin Chem 48:354-356

16. Wei JQ, Zhou XT, Wei JI 1987 Simultaneous measurement of eight corticosteroids by liquid chromatography, and application of the procedure to diagnosis of congenital adrenal hyperplasia. Clin Chem 33:1354-1359

17. Rauh M, Groschl M, Rascher W, Dorr HG 2006 Automated, fast and sensitive quantification of 17 alpha-hydroxy-progesterone, androstenedione and testosterone by tandem mass spectrometry with on-line extraction. Steroids 71:450-458

18. Kao PC, Machacek DA, Magera MJ, Lacey JM, Rinaldo P 2001 Diagnosis of adrenal cortical dysfunction by liquid chromatography-tandem mass spectrometry. Ann Clin Lab Sci 31:199-204

19. Caulfield MP, Lynn T, Gottschalk ME, Jones KL, Taylor NF, Malunowicz EM, Shackleton CH, Reitz RE, Fisher DA 2002 The diagnosis of congenital adrenal hyperplasia in the newborn by gas chromatography/mass spectrometry analysis of random urine specimens. J Clin Endocrinol Metab 87:3682-3690

20. Guo T, Chan M, Soldin SJ 2004 Steroid profiles using liquid chromatographytandem mass spectrometry with atmospheric pressure photoionization source. Arch Pathol Lab Med 128:469-475

21. Lacey JM, Minutti CZ, Magera MJ, Tauscher AL, Casetta B, McCann M, Lymp J, Hahn SH, Rinaldo P, Matern D 2004 Improved specificity of newborn screening for congenital adrenal hyperplasia by second-tier steroid profiling using tandem mass spectrometry. Clin Chem 50:621-625

22. Minutti CZ, Lacey JM, Magera MJ, Hahn SH, McCann M, Schulze A, Cheillan D, Dorche C, Chace DH, Lymp JF, Zimmerman D, Rinaldo P, Matern D 2004 Steroid profiling by tandem mass spectrometry improves the positive predictive value of newborn screening for congenital adrenal hyperplasia. J Clin Endocrinol Metab 89:3687-3693

23. Janzen N, Peter M, Sander S, Steuerwald U, Terhardt M, Holtkamp U, Sander J 2007 Newborn screening for congenital adrenal hyperplasia: additional steroid profile using liquid chromatography-tandem mass spectrometry. J Clin Endocrinol Metab 92:2581-2589

24. Janzen N, Sander S, Terhardt M, Peter M, Sander J 2008 Fast and direct quantification of adrenal steroids by tandem mass spectrometry in serum and dried blood spots. J Chromatogr B Analyt Technol Biomed Life Sci 861:117-122 